\title{
A Response to Concerns Raised for a Systematic Review and Meta-Analysis on Therapies for Pain in Parkinson's Disease
}

\author{
Abdul Rehman Qureshia,b Abdul Qayyum Rana ${ }^{a}$ Suleiman H. Malik ${ }^{a} \quad$ Shakib Akhter ${ }^{b}$ \\ ${ }^{a}$ Department of Neurology, Parkinson's Clinic of Eastern Toronto, Toronto, ON, Canada; ${ }^{b}$ Health Research Methods, \\ Evidence and Impact, McMaster University, Hamilton, ON, Canada
}

Dear Editor,

We appreciate the input given by the commentator for our study [1]. We would like to convey the following response to the concerns raised by the commentator for our systematic review and meta-analysis on therapies for pain in Parkinson's disease (PD) [2].

We acknowledge there is more to learn for the characterization, localization, severity, and interference of different pain types in PD and related disorders. We are aware of different pain subtypes, and we know that each may respond differently based on the treatment. We acknowledged that there are huge gaps in the literature and that pain remains poorly understood. Virtually all of the studies included in our review [2] reported a generic measure of pain severity, which limited the scope of our analysis. In our review, we came to realize that only one study adequately reported a categorical preand post-measurement of the frequency of 2 different types of pain (nocturnal and musculoskeletal) [3]. Although it must be considered that many of the studies in our review did not consider pain as a primary outcome, it is still unfortunate that when pain was reported as a secondary outcome, most studies only provided a complete pre- and post-assessment of pain through a quantitative measure of a "uniform" pain. Furthermore, many treatments that were compared had low sample sizes and high heterogeneity (e.g., miscellaneous therapies). However, the low or minimal heterogeneity seen in other subgroups (dopaminergic agonists, surgery, cannabinoids and opioids, and pardoprunox) suggests that the pain reduction effect was consistent in spite of pain subtype variation [2]. The efficacy of these treatments may only relate to a hypothetical average of all pain subtypes - an average that maybe heavily skewed by the most common subtypes - but this information may still have some clinical significance if the etiology of pain in a patient is not ascertained.

However, one perspective must be highlighted here. A concern for most patients is whether they may experience relief or cure from the experienced pain. Thus, the aspects mentioned about a uniform entity of pain being analyzed as opposed to the different types of pain being emphasized is catered to resolving problems through a patient-centred approach [4]. Focus on the specific type of pain may not be of importance in addressing pain concerns of a non-cancer patient. A large systematic review and meta-analysis of over 26,000 patients with non-chronic pain found that the type (or category) of pain was not a factor associated with a minimally important difference of pain relief by opioids relative to placebo [4]. Furthermore, the patient also perceives other dimensions such as quality of life, physical functioning and mental health as factors that are negatively impacted by their enduring pain [5]. In hindsight, we believe that a meta-regression should have been performed in our systematic review and meta-analysis to investigate correlations between pain and the said variables [5]. Future reviews on pain in PD are encouraged to take a patient-centred approach, where the emphasis is not on the intricate details of pain such as its subtypes in PD, but rather its etiology, and its relation to functional outcomes that are of concern to the patient.

\section{Acknowledgment}

None.

\section{Disclosure Statement}

The authors have no conflicts of interest to declare.

\section{Funding Sources}

There is no funding source to declare.
KARGER

() 2019 S. Karger AG, Basel 


\section{Author Contributions}

A.R.Q. and A.Q.R. conceptualized the design of the manuscript. S.A., A.R.Q., and S.H.M. were responsible for analysis and interpretation. A.R.Q. and A.Q.R. created the first draft, while all authors revised the draft for important intellectual content. All authors approved the final version of the manuscript and agreed to be accountable for all aspects of the work pertaining to the manuscript.

\section{References}

1 Raphael KG. Therapies for Pain in Parkinson Disease: Concerns Related to a Meta-Analysis on Treating Different Types of Pain as if They Were the Same. Neuroepidemiology. 2019; 52(1-2):74-5.

2 Qureshi AR, Rana AQ, Malik SH, Rizvi SF, Akhter S, Vannabouathong C, et al. Comprehensive examination of therapies for pain in Parkinson's Disease: a systematic review and meta-analysis. Neuroepidemiology. 2018; 51(3-4):190-206.

3 Trenkwalder C, Chaudhuri KR, Martinez-Martin P, Rascol O, Ehret R, Vališ M, et al.; PANDA study group. Prolonged-release oxycodone- naloxone for treatment of severe pain in patients with Parkinson's disease (PANDA): a double-blind, randomised, placebo-controlled trial. Lancet Neurol. 2015 Dec;14(12):1161-70.

4 Busse JW, Wang L, Kamaleldin M, Craigie S, Riva JJ, Montoya L, et al. Opioids for chronic noncancer pain: a systematic review and metaanalysis. JAMA. 2018 Dec;320(23):2448-60.

5 Busse JW, Bartlett SJ, Dougados M, Johnston BC, Guyatt GH, Kirwan JR, et al. Optimal strategies for reporting pain in clinical trials and systematic reviews: recommendations from an OMERACT 12 workshop. J Rheumatol. 2015;42(10):1962-70. 